\title{
Cuidar, exhortar y abrir el corazón: el epistolario de Elmina Paz de Gallo, Tucumán, Argentina (segunda mitad del siglo XIX)
}

\author{
Care, Exhortation and Opening the Heart: the Epistolary of Elmina Paz de \\ Gallo, Tucuman, Argentina (Second Half of the $19^{\text {th }}$ century)
}

\section{Cynthia Folquer}

UNIVERSIDAD DEL NORTE SANTO TOMÁS DE AQUINO (UNSTA), TUCUMÁN, ARGENTINA, cfolquer@unsta.edu.ar

El epistolario de Elmina Paz de Gallo, que aquí analizo, permite una aproximación al mundo conventual decimonónico, a las relaciones entre las religiosas, su cotidianidad en los asilosconventos, la construcción de la identidad religiosa, a la intimidad, las emociones, en definitiva se aborda una "escritura del alma". Presenta la vida de Elmina Paz, el contexto educativo del Tucumán decimonónico, las prácticas de lectura y escritura conventual y una selección de cartas agrupadas en torno a tres ejes: cuidado de la vida, intimidad y exhortación.

PaLABRAS Clave: mujer, vida religiosa, epístolas, Tucumán, siglo xIX.

The epistolary of Elmina Paz de Gallo analyzed in this article opens a window into the world of $19^{\text {th}}$-century convents, including such topics as relations among nuns, their everyday life in those asylum-convents, the construction of religious identities, and intimacy and emotions in those cloisters; in short, an examination of "writing from the soul". The essay focuses on the life of Elmina Paz, the context of education in $19^{\text {th }}$-century Tucumán, practices related to reading and writing in the convent, and a selection of letters grouped around three axes: caring for life, intimacy, and exhortation.

KEYWORDS: women, religious life, epistles, Tucumán, $19^{\text {th }}$ century.

Fecha de recepción del artículo: 22 de junio de 2015 / Fecha de aprobación: 29 de febrero de 2016 / Fecha de recepción de la versión final: 9 de marzo de 2016

\section{LA ESCRITURA CONVENTUAL EN LAS DOMINICAS}

\section{Y LA EDUCACIÓN DE LA MUJER EN EL SIGLO XIX EN TUCUMÁN}

\section{- os documentos que se conservan en el archivo de las domini- cas dan cuenta del proceso fundacional de esta congregación surgida en Tucumán (Argentina) ${ }^{1}$ y expresan autoría femeni-}

${ }^{1}$ Esta congregación religiosa surgió como consecuencia de la epidemia de cólera de 1886 que devastó la provincia y dejó gran cantidad de huérfanos, quienes fueron acogidos por un grupo de mujeres que se solidarizaron con ellos. 
na. Las crónicas, necrologías, informes, memorias, autobiografías, libros de cuentas, epistolarios etcétera, nos permiten abordar un mundo que se desarrolló al interior del claustro, pero que permaneció fuertemente arraigado en la sociedad de la época y permeable a su entorno. La importancia de la recuperación de los textos elaborados intramuros, en el periodo colonial hispanoamericano, fue puesta de manifiesto por estudiosas como Josefina Muriel, Asunción Lavrin, ${ }^{2}$ Electa Arenal, Stacey Schlau, Kathleen Myers, Jean Franco, Margo Glantz y Rosalva Loreto, por citar algunas. En Argentina fueron pioneros los trabajos de Alicia Fraschina, Gabriela Braccio y Victoria Cohen Imach sobre escritura conventual del periodo colonial y del siglo xIx. Este camino de investigación es deudor de las intuiciones de estas autoras como también de los trabajos sobre congregaciones femeninas del siglo XIX realizados por Sol Serrano en Chile y Elizabeth Dufourq en Francia. ${ }^{3}$

En otros trabajos he abordado el estudio de cartas de Fr. Ángel María Boisdron, ${ }^{4}$ quien fue colaborador de Elmina Paz-Gallo en la

${ }^{2}$ Los textos pioneros de epístolas conventuales en América Latina de Asunción Lavrin fueron una inspiración de mis estudios: "De su puńo y letra: epístolas conventuales", en El monacato femenino en el imperio español, coord. Manuel Ramos Medina (México: CONDUMEX, 1995), 43-62; "La celda y el siglo: epístolas conventuales", en Mujer y cultura en la Colonia hispanoamericana, ed. Mabel Morańa, 139-159 (Pittsburg: Instituto Internacional de Literatura Iberoamericana, 1996). Véanse también las compilaciones de Asunción Lavrin y Rosalva Loreto López, eds., Monjas y beatas. La escritura femenina en la espiritualidad barroca novohispana. Siglos XVII y XVIII (México: Universidad de las Américas, Puebla, Archivo General de la Nación, México, 2002); Asunción Lavrin y Rosalva Loreto López, eds., Diálogos espirituales. Manuscritos femeninos hispanoamericanos. Siglos XVI-XIX (México: Universidad Autónoma de Puebla, Universidad de las Américas-Puebla, 2006); Asunción Lavrin, "Los senderos interiores de los conventos de monjas", Boletín de Monumentos Históricos, 3a Época (30) (enero-abril 2014): 6-21.

${ }^{3} \mathrm{Me}$ refiero a los siguientes textos: Sol Serrano, Virgenes viajeras. Diarios de religiosas francesas en su ruta a Chile. 1837-1874 (Santiago: Universidad Católica de Chile, 2001); "El poder de la obediencia: religiosas modernas en la sociedad chilena del siglo XIX, en Las mujeres en la construcción de las sociedades iberoamericanas, coord. Pilar Gonzalbo Aizpuru y Berta Ares Quija, 295-313 (Sevilla, México: Consejo Superior de Investigaciones Científicas, El Colegio de México); Elizabeth Dufourq, Les Aventurières de Dieu, trois siècles d'histoire missionnaire française (París: Du Cerf, 2009).

${ }^{4}$ Cynthia Folquer, "La construcción de la subjetividad femenina en Tucumán. Las epístolas de Fray Boisdron (1891-1920)”, Telar (4) (2006): 70-93; “Escribir de sí: interioridad y política en las mujeres de Tucumán (fines de siglo XIX y principios del xx", en Sociedad, cristianismo y politica. Tejiendo historias locales, coords. Cynthia Folquer y Sara 
fundación de las dominicas de Tucumán. Es mi propósito en este trabajo indagar en las epístolas escritas por esta mujer fundadora. El valor documental de los epistolarios para la historia de la escritura femenina y, en especial, para la escritura conventual ha sido señalado por investigadores de larga trayectoria, como afirman Nieves Baranda Leturio y María del Carmen Marín Pina, los epistolarios comienzan a ser considerados como una fuente valiosa para conocer las profundidades del mundo conventual, el viaje y la historia fundacional, la sociabilidad, las relaciones espirituales o la cotidianidad. ${ }^{5}$ Así también, el epistolario de Elmina Paz preservado en el archivo conventual y en los archivos de miembros de la familia Paz, ${ }^{6}$ demuestra la voluntad de conservación como estrategia que denota la importancia dada a este corpus concreto. Estas cartas revelan aspectos inéditos de la vida cotidiana, trasparentan estados de ánimo, la intimidad de la escritora, verdadera escritura del alma, como bien señala Gabriela Zarri para cartas conventuales de otros contextos. ${ }^{7}$

La documentación escrita por las dominicas conservada en el archivo, manifiesta diversos grados de formalización cultural de las escritoras. La situación geográfica de Tucumán, los condicionamientos socioeconómicos y culturales, ubica a esta provincia en un lugar periférico respecto a los centros más importantes de la Argentina y Latinoamérica decimonónica. Este lugar marginal se pone de manifiesto en la escasa accesibilidad a la educación formal de la población tucumana y de las mujeres en particular. Este contexto explica las características lingüísticas y estilísticas de los textos que produjeron. ${ }^{8}$ Otras ciudades de América Latina y Argentina tuvie-

Amenta, 191-228 (Tucumán: UnSTA, 2010); “Aprendiendo a hablar de sí misma. Las cartas de Fr. Ángel Boisdron a Sr Juana Valladares”, Revista Itinerantes. Historia y Religión (1) (2011): 159-178.

${ }^{5}$ Nieves Baranda Leturio y María del Carmen Marín Pina, "El universo de la escritura conventual femenina: deslindes y perspectivas", en Letras en la celda. Cultura escrita de los conventos femeninos en la España moderna, ed. Nieves Baranda Leturio y María Marín Pina, 33 (Madrid y Frankfurt: Iberoamericana-Vervuert, 2014).

${ }^{6}$ Han sido un gran aporte a esta investigación los archivos privados de las familias Nougues-Paz y Wright-Paz.

${ }^{7}$ Gabriela Zarri, "La scriturra monástica", en Letras en la celda, 57.

${ }^{8} \mathrm{Me}$ ha resultado muy sugerente el estudio introductorio del epistolario de la dominica chilena sor Dolores Peńa y Lillo, realizado por Raïssa Kordi Riquelme, sigo en mi 
ron para la segunda mitad del siglo XIX mejores niveles de formalización educativa y las mujeres produjeron obras más próximas a los cánones con recursos lingüísticos más logrados.

En Tucumán a mediados de siglo xix, las mujeres mostraban una educación menos formalizada, y la producción escrita de mujeres fue escasa en comparación con otras regiones centrales de la cultura latinoamericana como Buenos Aires, Lima, Quito, Bogotá o México. ${ }^{9}$

La primera biógrafa de la fundadora Elmina Paz, la hermana Tomasa Alberti, se refería a la educación recibida por esta mujer de la elite a mediados del siglo xIx y afirmaba que:

sus padres que se preocuparon siempre por la formación moral e intelectual de sus hijos, pusieron a esta niña privilegiada, una maestra, la Srta Ercilia del Corro, la que conjuntamente con su dignísima madre, dirigíanla, inculcando y vigorizando en esta tierna planta, los más sólidos conocimientos de nuestra santa religión; a lo que ella correspondía con decisión, fortaleciendo su alma con esta savia divina. ${ }^{10}$

análisis algunos de sus postulados, que aunque se refieren al siglo XvIII, he encontrado grandes coincidencias con los rasgos de la escritura conventual femenina del siglo XIX que intento analizar. Agradezco a Miguel Zugasti el haberme sugerido la lectura de este libro y su envío desde España. Véase Raïssa Kordic Riquelme, "Prólogo y edición crítica", Epistolario de sor Dolores Peña y Lillo (Chile, 1763-1769) (Madrid: Universidad de Navarra, Iberoamericana-Vervuert, 2008).

${ }_{9}^{9}$ Por nombrar sólo algunas de las mujeres escritoras del siglo xIx podemos mencionar a Juana Manso, Juana Manuela Gorriti, Eduarda Mancilla de García, Rosa Guerra (Argentina); Carolina Freire de Jaimes, Clorinda Matto de Turner, Mercedes Cabello de Carbonera (Perú); Soledad Acosta de Samper (Colombia); Laureana Wrigth de Kleinhans (México); Gertrudis Gómez de Avellaneda (Cuba). Para un análisis del nivel educativo de estas autoras véase Nina Scott, "Escritoras hispanoamericanas del siglo xIX", en Historia de las mujeres en España y América Latina, vol. III, dir. Isabel Morant, 693-721 (Madrid: Cátedra, 2006). Agradezco a Victoria Cohen Imach la sugerencia de este texto y sus interesantes aportes en el curso 2013 sobre escritoras latinoamericanas del siglo XIX en la Universidad Nacional de Tucumán. Sobre las mujeres escritoras argentinas, es ineludible la compilación de Lea Fletcher, Mujeres y cultura en la Argentina del siglo XIX (Buenos Aires: Feminaria, 1994). También para un panorama de la educación de las mujeres en América Latina, hacia fines del siglo xix, véase el texto de síntesis de Lucía Lionetti, "La educación de las mujeres en América Latina: formadoras de ciudadanos", en Historia de las mujeres en España y América Latina, 849-869.

${ }^{10}$ Tomasa Alberti, Vida de Sor Dominga del Ssmo Sacramento Paz-Gallo, 1934, f. 4. Carpeta: Escritos sobre Elmina Paz-Gallo. Archivo de las Hermanas Dominicas de Tucumán (АНDT). 
Esta referencia a la maestra del Corro y la tarea materna en la formación "moral e intelectual" nos remite a la situación de la educación en la provincia de Tucumán a mediados del siglo xIx. Según explica Norma Ben Altabef, ${ }^{11}$ para este periodo, la propuesta educativa se regía por el modelo colonial, donde las órdenes religiosas eran las instituciones a quienes se les encomendaba esta tarea. En Tucumán principalmente fueron los franciscanos, ${ }^{12}$ los que impartieron una educación básica en una escuela conventual, que ofrecía a los niños la enseñanza de las primeras letras y el catecismo. Estas escuelas conventuales acogían casi exclusivamente a varones de manera que las mujeres eran enviadas a docentes particulares que atendían a sus alumnas en sus domicilios, que acordaban contenidos y precios de la enseñanza con sus padres. Para estas primeras décadas del siglo XIX, aprender a leer y escribir "dependía muchas veces del contacto con algún adulto letrado, ya sea que perteneciese a los grupos sociales principales o que estuviera cerca de ellos". ${ }^{13}$

En 1859 se inauguró el primer colegio para mujeres, el Colegio de Beneficencia, para que "las jóvenes pudieran recibir una educación esmerada en armonía con el rol distinguido que esta preciosa mitad está llamada a desempeñar en el grado de cultura a que ha llegado la sociedad tucumana" ${ }^{14}$ La primera directora fue Dolores Salas, antigua rectora del Colegio de Educandas de Salta, uno de los primeros establecimientos para mujeres que existió en el noroeste argentino. Esta iniciativa era llevada a cabo por la Sociedad de Beneficencia que había sido fundada pocos años antes en Tucumán, en 1852, por decreto del gobernador Marcos Paz y que también tenía a su cargo el Hospital de Caridad.

${ }^{11}$ Norma Ben Altabef, "Educar en Tucumán en la primera mitad del siglo xIx. El modelo pedagógico colonial y el nuevo modelo educativo. Permanencias e iniciativas", en La república extraordinaria. Tucumán en la primera mitad del siglo XIX, coord. G. Tío Vallejo, 253-313 (Rosario: Prohistoria, 2011).

${ }^{12}$ La primera escuela conventual franciscana fue establecida en 1566 por los frailes que acompañaron la primera fundación de la ciudad. Manuel Solari, Historia de la educación Argentina (Buenos Aires: Paidós, 1972), 18.

${ }^{13}$ Norma Ben Altabef, "Educar en Tucumán”, 277.

14 "La escuela primaria en Tucumán", en Album general de la Provincia de Tucumán en el primer Centenario de la Independencia Argentina (Buenos Aires: Establecimiento Gráfico Rodríguez Giles, 1916). 
El primer espacio de educación secundaria para mujeres fue el Colegio Particular Sarmiento, ${ }^{15}$ creado en 1870 y dirigido por Benigna Saravia, una educadora salteña de gran trayectoria. En 1877, este colegio fue confiado a las hermanas del Huerto, quienes provenientes de Italia se establecieron en Tucumán renovando la enseñanza primaria y secundaria para mujeres. La sociedad de las Hijas de María se constituyó en el sostén económico de este establecimiento.

En la memoria del Álbum general de la Provincia de Tucumán en el primer Centenario de la Independencia Argentina, citado con anterioridad, se dejó constancia de las "escuelas antiguas que dejaron huellas duraderas, las de las señoras Trinidad Castor del Corro, su hermana doña Juana Castro y de doña Benigna Saravia”. A estas escuelas particulares que funcionaban en los espacios domésticos de quienes ejercían como maestras, se refiere la biógrafa de Elmina Paz al nombrar a la Srta. del Corro, maestra de Elmina Paz como ya lo mencionamos.

Fue en 1888 cuando comenzó a funcionar la Escuela Normal de Maestras independiente de la Escuela Normal Mixta, fue su primera directora Delia Robles Madariaga. A este esfuerzo de formación de maestras se sumó la Escuela Pedagógica Sarmiento, que comenzó a funcionar en 1904. En el mismo periodo Elmina Paz y las dominicas de Tucumán abrían un nuevo colegio para señoritas en la ciudad de Monteros en 1895, y otro en la ciudad de San Miguel de Tucumán en 1902, con el objetivo de propiciar a las mujeres una educación de excelencia, de manera que "al igual que las europeas pudiesen ser doctoras en leyes, letras o medicina". ${ }^{16}$

Como hemos visto un incipiente sistema educativo comenzó a establecerse en Tucumán de manera más estable hacia la segunda mitad del siglo xix. Esta provincia, signada por la marginalidad geográfica y los escenarios de guerra que implicaban levas permanentes,

${ }^{15}$ Rodolfo Cerviño, "El primer colegio secundario de mujeres en Tucumán, Colegio Sarmiento", Revista de la Junta de Estudios Históricos de Tucumán, año 7(4) (julio 1974): 189-238.

${ }^{16}$ Con estas palabras Fr. Boisdron cerraba el ciclo lectivo del Colegio Santa Rosa en 1908. Ángel María Boisdron, "La intelectualidad de la mujer", Discursos y escritos (Buenos Aires: Presuche y Eggeling, 1921), 157-160. 
dificultó que el incipiente estado provincial pudiera asumir la organización de un sistema educativo público. ${ }^{17}$

Este breve recorrido por la historia de la educación en Tucumán, nos permite ubicar las posibilidades de formación que tuvo Elmina Paz-Gallo. Considerando que Elmina nació en 1833, su edad de escolaridad puede ubicarse entre 1840-1850, podemos inferir que transcurrió en una etapa donde la inexistencia de escuelas hacía forzoso buscar espacios educativos en maestras particulares. La educación en estas escuelas particulares se limitaba al catecismo y las primeras letras, por ello podemos corroborar que Elmina Paz tuvo un bajo nivel de educación formalizada. Su estilo de escritura adquiere notable mejoría cuando es una amanuense ${ }^{18}$ quien redacta. ${ }^{19}$

\section{Elmina Paz-Gallo: de mujer de elite a madre DE LOS POBRES Y CONSAGRADA A Dios}

Elmina Paz-Gallo ${ }^{20}$ nació en Tucumán el 10 de septiembre de 1833 y falleció el 1 de noviembre de 1911. Hija de Manuel Paz, un rico hacendado, ${ }^{21} \mathrm{y}$ de Dorotea Terán, quien fuera la primera presidenta

${ }^{17}$ Norma Ben Altabef, "Educar en Tucumán”, 271-279.

${ }^{18}$ Me ha resultado interesante la lectura del texto de Elena Giménez Alvira, "Cartas al dictado". El epistolario de la Madre Isabel de Santo Domingo (Convento de San José de Carmelitas descalzas de Zaragoza)", en Letras en la celda, 255-271.

${ }^{19} \mathrm{El}$ rol de la amanuense o secretaria fue fundamental para Elmina Paz, ya que los últimos años se vio impedida de escribir debido a una fractura de cadera que la hizo permanecer mucho tiempo en cama. Necrología de Elmina Paz (AHDT). La amanuense era la depositaria de sus confidencias, según la tradición oral, Elmina solía dictar sus cartas a la Hna. Rafaela Alves, y como de costumbre comenzó nombrando a la destinataria como "Querida". Ante ello Elmina le advirtió: "a esta persona no la nombré como querida, porque no la estimo tanto". Testimonio de Teresa María Gallardo, entrevista realizada en Tucumán, 10 de abril de 2014.

${ }^{20}$ Para una biografía de Elmina Paz, véase María Haydée Herrera, Elmina Paz. Heredera e iniciadora. Una biografía teológica (Tucumán: UNSTA, 2011). Para otra aproximación a su vida léase Cynthia Folquer, "Olvidarme de mí: Elmina Paz o la cuestión del otro", Revista Duoda, Estudios de la Diferencia Sexual (34) (2008): 33-54.

${ }^{21}$ He realizado un estudio de la familia Paz en Cynthia Folquer, "La elite local de Tucumán en la construcción del estado-nación argentino. El caso de Benjamín Paz y Elmina Paz de Gallo (fines del siglo XIX-principios del siglo xx)", Revista de Indias LXVII(240) (2007): 433-458. 
de la Sociedad de Beneficencia de Tucumán. ${ }^{22}$ Manuel Paz realizó una intensa actividad de compra de tierras, sitios, casas, fincas y estancias, desde 1832 hasta 1860 . Sus ocho hijos, Manuel, Isabel, Elmina, Leocadio, Benjamín, Dorotea, Esilda y Mercedes realizaron, a su vez, enlaces matrimoniales con familias de la elite hacendada o industrial de Tucumán, Santiago del Estero y Córdoba. La tercera generación continuó fortaleciendo las redes de sociabilidad y vínculos que posicionaron a la familia Paz en un sólido entramado de lazos de sangre, alianzas políticas y económicas. Las alianzas matrimoniales fueron las siguientes: Manuel Paz-Donatila Peña Funes (Córdoba); Isabel Paz-Javier López; Elmina Paz-Napoleón Gallo, industrial y político santiagueño; Leocadio Paz ${ }^{23}$-Ángela Colombres; Benjamín Paz ${ }^{24}$-Dalmira Colombres; Dorotea PazRufino Cossio ${ }^{25}$ (uno de los más ricos comerciantes y hacendados de la provincia); Esilda Paz-Florencio Sal; Mercedes Paz-Bernardo Colombres.

Elmina Paz contrajo matrimonio con Napoleón Gallo, ${ }^{26}$ en 1857, a la edad de 24 años. Establecieron su domicilio en Santiago del Estero donde nació su única hija, María Jesús quien murió a la edad de 4 años. Vivieron varios años en Santiago del Estero hasta que finalmente la pareja se radicó en San Miguel de Tucumán, donde la familia Gallo poseía un ingenio azucarero, razón por la cual Napoleón se dedicó a la industria. Napoleón falleció en julio de 1886 pocos meses antes de que la epidemia de cólera ${ }^{27}$ azotara la

${ }^{22}$ Este nombramiento como presidenta de la Sociedad de Beneficencia da cuenta del lugar social de preeminencia de la madre de Elmina Paz.

${ }^{23}$ Leocadio fue un gran hacendado, poseedor de curtiembres e industrial azucarero.

${ }^{24}$ Benjamín fue uno de los políticos notables de la provincia de Tucumán, jurista, gobernador, senador, ministro de Interior de la nación y presidente de la Corte Suprema de Justicia de la Nación. Me he referido a su trayectoria en la obra ya citada, Cynthia Folquer, "La elite local de Tucumán".

${ }^{25}$ Rufino fue uno de los más ricos comerciantes y hacendados de la provincia.

${ }^{26}$ Nació en Santiago del Estero el 1 de enero de 1819 y fallecido en Tucumán en julio de 1886. Perteneció a la elite de Santiago del Estero, su familia se sumó a las inversiones en la industria azucarera, siendo los dueños del ingenio Luján en Tucumán. Napoleón fue un hombre de fuerte militancia política, motivo por el cual se vio envuelto en conflictos de facciones, lo que le obligó a huir de la ciudad con su familia en varias ocasiones.

${ }^{27}$ He abordado la cuestión del cólera en Cynthia Folquer, "Cólera morbus y cólera 
ciudad y a otras de Argentina. Esta epidemia fue particularmente cruenta en Tucumán por no contar el estado provincial con una organización sanitaria que pudiera establecer una barrera eficaz a ese terrible flagelo. La epidemia diezmó la población de la provincia, que para esa época alcanzaba los 100,000 habitantes. ${ }^{28} \mathrm{~A}$ fines de 1886, Elmina Paz, a la edad de 54 años, convirtió su casa en asilo para huérfanos y en junio de 1887 estableció las bases de lo que sería la congregación de dominicas de Tucumán.

Elmina Paz había ejercido entre 1877 y 1878 -al igual que su madre lo hiciera con anterioridad- la presidencia de la Sociedad de Beneficencia de Tucumán, esta responsabilidad le implicaba la gestión de algunas casas de caridad establecidas en la ciudad que conducían las damas de beneficencia. Al fundar la congregación no sólo organizó varios asilos y escuelas para huérfanos en distintas provincias de Argentina, sino que tuvo la tarea de acompañar la formación y crecimiento espiritual de las nuevas religiosas. En esta tarea tuvo la especial ayuda de Fr. Ángel María Boisdron, un fraile dominico francés que se había establecido en Tucumán, quien se había comprometido desde los inicios en este proyecto de ayuda a los nińos desprotegidos. El vínculo entre el grupo de mujeres fundadoras y el fraile de la Orden de Predicadores influyó para que la naciente congregación religiosa asumiera la tradición espiritual de la Orden Dominicana.

divina. Miedo, epidemia e imaginario religioso. Tucumán, 1886-1887”, Boletín Americanista, ańo LXI (62) (2011): 73-96. También sobre la epidemia en Tucumán son interesantes los aportes de Vanesa Teiltelbaum, "Hacia una política social. Higiene y trabajo en Tucumán del entresiglo”, Anuario IEHS (24) (2009): 41-68 y María Cecilia Gargiulo, "El cólera: oportunidades de control y resistencias populares. Tucumán, 1886-1887", Estudios Sociales, año Xxi (41) (segundo semestre 2011): 97-125.

28 "El incremento poblacional fue particularmente notable en la segunda mitad del siglo XIX debido a la modernización y primer ciclo expansivo de la industria azucarera. En efecto, entre 1858 y 1869 el número de habitantes de la provincia se incrementó de 83,544 a 108,953 y en 1895 alcanzó a 215,742. El centro más poblado era la ciudad de San Miguel de Tucumán, que en 1869 tenía 17,438 habitantes y hacia 1895 pasó a albergar alrededor de 34,000". Datos extraídos del Primer Censo de la República Argentina de 1869 y del segundo censo de 1895. Véase Paula Parolo, Daniel Campi y María Estela Fernández, "Auge azucarero, mortalidad y políticas de salud en San Miguel de Tucumán en la segunda mitad del siglo XIx, Estudios Sociales, Revista Universitaria Semestral, año xx(38) (primer semestre 2010): 39-72. 
En el proyecto de consolidar la formación del primer grupo de mujeres encargadas del asilo de huérfanos que había decidido asumir la vida consagrada, las lecturas se constituyeron en el instrumento más apropiado para iniciarse en el nuevo estilo de vida elegido. Los libros antiguos de la biblioteca conventual reflejan el tipo de lecturas a las que tenían acceso y la cultura bibliográfica de las dominicas de Tucumán. El análisis de esta biblioteca como bien afirma Aracelli Rosillo Luque, ${ }^{29}$ "se inscribe dentro de una historiografía que entiende a las mujeres como sujetos que elaboran sus propios discursos de vivencia y convivencia dentro de la clausura".

Entre los libros más antiguos (mediados del siglo xix) podemos encontrar las siguientes temáticas: teología espiritual, vida de santos, literatura griega, sistemas pedagógicos, historia y teología dogmática. Entre los autores figuran Agustín de Hipona, Tomás de Aquino, Catalina de Siena, Raimundo de Capua, Luis de Granada, Enrique Susón, Ignacio de Loyola, Juan de la Cruz, Teresa de Ávila, María Jesús de Agreda, Francisco de Sales, Alfonso María de Ligorio, Vicente Ferrer, Hansen, entre otros.

Estos libros hablan de las mujeres que los buscaron, encargaron, compraron y conservaron, están en estrecha relación con ellas, dan una idea de las lecturas personales o comunitarias, de los hábitos de lectura y de las tendencias espirituales que circulaban por el Tucumán decimonónico. Estas lecturas constituyeron las principales fuentes de influencia para Elmina Paz, si bien no podemos postular una certeza absoluta de las lecturas realizadas, la presencia de estos libros habla de una decisión de compra y sabemos que la lectura espiritual era un mandato de la regla de vida religiosa dominicana que se debía realizar a solas y en comunidad. La correspondencia, analizada en otros trayectos de investigación, pone de manifiesto que

${ }^{29}$ Aracelli Rosillo Luque, "La biblioteca antigua del convento de dominicas de Ntra. Sra. dels Àngels i Santa Clara de Manresa (siglos XVII-XIX): notas para su estudio a partir del inventario", Letras en la celda. Cultura escrita de los conventos femeninos en la España moderna, ed. Nieves Baranda Leturio y María Marín Pina, 238 (Madrid y Frankfurt, Iberoamericana-Vervuert, 2014). 
Fr. Boisdron fue un canal fundamental para el acceso de las mujeres a los libros, ya que en muchas ocasiones fue el intermediario de la compra de libros encargados a libreros de España o quien fomentó su lectura, introduciendo a la nueva congregación en la tradición dominicana. Así, figuras como Catalina de Siena, Rosa de Lima, Enrique Susón y fray Luis de Granada, marcaron el camino espiritual por el que transitaron las tucumanas. La lectura operaba como principal instrumento de instrucción otorgando el sentido a los actos religiosos, fortalecía la pertenencia a la Orden Dominicana, a la vez que transmitía tradiciones, consolidaba la identidad grupal y configuraba gestos, prácticas e imágenes, actuando como elemento socializador, de igual manera como lo señala Alicia Fraschina para el caso de las dominicas de Buenos Aires en el periodo colonial ${ }^{30}$ o Kordic Riquel$\mathrm{me}^{31}$ para el caso de las dominicas de Chile del mismo periodo. Se leía en comunidad en el refectorio, en la sala de recreación, en la capilla o a solas en la intimidad de la celda. La lectura diaria de las Constituciones y la Regla de San Agustín consolidaban la integración comunitaria. Conviene señalar aquí las lecturas aconsejadas para la formación de las postulantes y novicias: vida de los santos dominicos y libros de autores como san Bernardo, san Vicente Ferrer, santa Catalina de Siena, del Venerable Humberto, Luis de Granada y santa Teresa de Jesús. ${ }^{32}$ Junto a estas lecturas se encontraban una cantidad de devocionarios con propuestas de meditación sobre los misterios del rosario y las "llagas de Jesucristo", entre muchos otros.

La Summa Theologica de santo Tomás de Aquino, los textos de Bossuet, Chateaubriand, Pallés, Lacordarie y Monsabré, constituían otro grupo importante de textos recogidos en la biblioteca de las dominicas, obras dirigidas a completar la formación espiritual y doctrinal. Además debía leerse el Manual de Urbanidad de Carreño, que actuó como instrumento de civilidad al interior del convento. ${ }^{33}$

${ }^{30}$ Alicia Fraschina, Mujeres consagradas en el Buenos Aires colonial (Buenos Aires: Eudeba, 2010).

${ }^{31}$ Raïssa Kordic Riquelme, "Prólogo y edición crítica”, Epistolario de sor Dolores Peña y Lillo (Chile, 1763-1769) (Madrid: Universidad de Navarra, Iberoamericana-Vervuert, 2008).

${ }^{32}$ Constitución de las Hermanas Dominicas de Tucumán, República Argentina (Friburgo: Imprenta y Librería de la Obra de San Pablo, 1893).

${ }^{33}$ Entre los libros antiguos que se conservan podemos citar, a título de ejemplo, Al- 
Las lecturas fueron configurando las representaciones que las religiosas tenían de sí mismas y de su realidad, pero no sólo se hacían semejantes a lo que leían, sino que hacían semejantes las lecturas a lo que ellas eran y vivían en el proceso de apropiarse y reapropiarse de los textos. ${ }^{34}$ Las dominicas no constituyeron un público pasivo de lectoras que consumían pasivamente los diferentes libros de espiritualidad que llegaban a sus manos, sino que enfrentaban esos libros con creatividad. Como lectoras no fueron sólo receptoras de modelos que debían reproducir, sino que reelaboraban los textos según su propia creatividad. ${ }^{35}$ Como bien expresa de Certeau, leer es peregri-

fonso María de Ligorio, La verdadera esposa de Jesucristo o sea la monja santa (Barcelona: Pons y Compa. Editores Católicos, 1892); Louis Emile Bougaud, Historia de Santa Juana Francisca Fremiot, Baronesa de Chantal, Fundadora de la Orden de la Visitación de Santa Maria, llamada vulgarmente de Religiosas Salesas y del Origen de este santo Instituto, 2 vols. (Madrid: Imprenta de Don Luis Agudo, 1889); Jacques Bénigne Bossuet, Discurso sobre la historia universal (París: Garnier Hermanos, 1896); Manuel Antonio Carreño, Manual de urbanidad y buenas maneras para uso de la juventud de ambos sexos en el cual se encuentran las principales reglas de civilidad y etiqueta que deben observarse en las diversas situaciones sociales: precedido de un breve tratado Sobre los deberes morales del hombre (Nueva York: D. Appleton y Compañía, 1887); François de Chauteaubriand, El genio del cristianismo o bellezas de la religión cristiana (Madrid: Saturnino Calleja, 1876); Francisco de Sales, Entretenimientos espirituales de S. Francisco de Sales, obispo, doctor de la Iglesia y Fundador de la Orden de la Visitación a los que van añadidos algunos opúsculos del mismo santo (Barcelona: Librería Religiosa, 1881); Luis de Granada, Catalina de Siena, Enrique Susón, Meditaciones para todos los días de la semana (Madrid: Librería Católica de Gregorio del Amo, 1897); Fray Luis de Granada, Guía de pecadores: en la cual se contiene una larga y copiosa exhortación a la virtud y guarda de los mandamientos divinos (París: Librería de Garnier Hermanos, 1880); Benigno T. Martínez, Antología argentina: colección de trozos históricos critico-literarios. Discursos y poesías patrióticas de escritores argentinos en prosa y verso (Buenos Aires: Casa Editora Imprenta, Litografía, Librería y Encuadernación de J. Peuser, 1890); Jacques Marie Louis Monsabré, Exposición del dogma católico. Cuaresma 1888-90 (La vida futura. Vergara, Tip. de "El Santísimo Rosario", 1894); Charles Montalembert, Historia de Santa Isabel de Hungría, duquesa de Turingia (1207-1231) (Barcelona: Librería Religiosa, 1891); José Pallés, Año de María o colección de noticias históricas, leyendas, ejemplos, meditaciones, exhortaciones y oraciones para honrar a la Virgen María en todos los días del año (Barcelona: Imprenta y Librería Religiosa y Científica, 1877).

${ }^{34}$ Sigo a Michel de Certeau en su sugerente abordaje sobre la práctica de la lectura, "Leer una cacería furtiva", en La invención de lo cotidiano I. Las artes de hacer (México: Universidad Iberoamericana, 2000), 177-189.

${ }^{35}$ Las epístolas, biografías, memorias, necrologías, crónicas y otros escritos, que se conservan en el archivo conventual de Tucumán, reflejan sus propias interpretaciones de los textos bíblicos, de los libros de espiritualidad y de la vida de los santos, manifestando un ejercicio de su libertad. 
nar en un sistema impuesto, pero los signos verbales o icónicos son una reserva que espera que el lector le otorgue un sentido, por ello, el libro puede ser comprendido como un efecto del lector, una producción propia de quien lee. Las dominicas tenían en sus Constituciones la recomendación del ejercicio diario de lectura espiritual "para instruirse en la doctrina de Jesucristo y de los Santos y alimentar a su alma con los ejemplos de ellos". En este ejercicio ellas se permitieron una "plularidad indefinida de significaciones". ${ }^{36}$ Se introducían en una "cacería furtiva" ${ }^{37}$ al leer, y buscaron vivir la libertad de leer como actividad silenciosa, en el espacio reservado de su celda y de manera independiente de los maestros de interpretación de turno, dan testimonio de esto las cartas, crónicas y testimonios orales recogidos de las religiosas ancianas de la congregación.

Los libros de la biblioteca antigua de las dominicas, en muchos de los cuales figuran los nombres de sus lectoras y las cartas escritas por ellas evocando dichas lecturas, revelan el acto de leer como experiencia iniciática, como muy bien explica De Certeau, "leer es estar en otra parte, allí donde ellos no están y en otro mundo [...] leer es crear rincones de sombra y de noche en una existencia sometida a la transparencia" ${ }^{38}$ A propósito de la lectura, Fr. Boisdron escribía a la Hna. Catalina Zavalía evocando un libro recibido: "en mi última carta me olvidé decirle que había recibido el primer tomo de las cartas de Santa Catalina de Siena. ¡Cartas tan llenas de fuego divino! Nos comunicara siquiera algunas centellas de esta ardiente caridad". 39

Las dominicas de Tucumán fueron lectoras y por ello nómades, "cazadoras furtivas" a través de los campos que no habían escrito.

${ }^{36}$ Michel de Certeau, "Leer una cacería furtiva", 182.

${ }^{37} \mathrm{La}$ imagen de los lectores como cazadores furtivos en las tierras del prójimo que utiliza De Certeau, sugiere una recuperación del rol del lector como aquel que puede introducirse en los recovecos y desviaciones que la página habilita, adiestrando en su ojo viajero, en los vuelos imaginarios o meditativos a partir de algunas palabras que este cazador furtivo realiza, cabalgando sobre las superficies militarmente ordenadas de lo escrito. Véase Michel de Certeau, "Leer una cacería furtiva", 183.

${ }^{38}$ Michel de Certeau, "Leer una cacería furtiva", 186.

${ }^{39}$ Carta de Fr Boisdron a la Hna Catalina Zavalía, Tucumán, agosto de 1911. Epistolario de Boisdron. Cartas de Boisdron a Catalina Zavalía, Archivo Hermanas Dominicas de Tucumán (AHDT). 
ENTRE EL CLAUSTRO Y LA ACCIÓN SOCIAL: LAS PRÁCTICAS EPISTOLARES ENTRE LAS DOMINICAS DE TUCUMÁN EN LA SEGUNDA MITAD DEL I 800

La producción escrita de mujeres fue escasa en el Tucumán decimonónico, en comparación con otras regiones centrales de la cultura latinoamericana como lo señalamos con anterioridad. A pesar del escaso nivel de formalidad cultural de las mujeres en esta región de Argentina, las dominicas cultivaron el género epistolar, practicándolo con asiduidad. Las cartas en la vida conventual cobraron importancia y fueron fundamentales en la conformación de la identidad religiosa de las mujeres.

En este trayecto de mi investigación pretendo avanzar en un territorio no suficientemente explorado: la escritura epistolar conventual en Tucumán de la segunda mitad del siglo XIX.

El libro de Meri Torras Francès, Tomando cartas en el asunto. Las relaciones peligrosas de las mujeres con el género epistolar, ${ }^{40}$ revela la afinidad de las mujeres con el intercambio de cartas en el siglo XVII y XVIII francés y la importancia de la práctica conversacional como núcleo de la cultura de las "preciosas". Para estudiar a las Mesdames y las Mademoiselles en los ámbitos de la sociabilité mundana propia de la nobleza parisina, durante los siglos XviI y XviII, Benedetta Craveri, acude, de modo recurrente, a los epistolarios que cuidadosamente estas mujeres se encargaron de ordenar y legar a la posteridad. Para las mundanas y los mundanos las cartas eran conversaciones por escrito que se leían y discutían en voz alta en el marco de las reuniones sociales. Además, la carta escondía una beta biográfica que para los historiadores representa una vía fundamental para indagar las manifestaciones de la sensibilidad de las generaciones pasadas. Craveri afirma que "desde los orígenes de la cultura mundana las mujeres de la buena sociedad demostraron poseer, más que nadie, el talento de la conversación y el secreto de la escritura epistolar". ${ }^{41} \mathrm{La}$

${ }^{40}$ Meri Torras Francès, Tomando cartas en el asunto. Las relaciones peligrosas de las mujeres con el epistolar (Zaragoza: Prensa Universitaria, 2001).

${ }^{41}$ Benedetta Craveri, La cultura de la conversación (Buenos Aires: Fondo de Cultura Económica, 2004), 382. 
práctica de aquellas mujeres nobles trasuntó al universo femenino burgués decimonónico y de allí a la condición femenina en general. En tal sentido, la correspondencia es una fuente adecuada y no alternativa para construir la historia de las mujeres.

La epístola fue el principal instrumento para superar las barreras espacio-temporales de la vida conventual de las dominicas de Tucumán. La correspondencia generó relaciones epistolares que contribuyeron a forjar identidades personales y colectivas y se constituyó en un instrumento fundamental de articulación de la subjetividad e interiorización de diversas dimensiones culturales. ${ }^{42}$ Las cartas nos ceden el paso a los registros de la experiencia individual, pues, permiten abordar el núcleo de la intimidad posicionando a la misma en el discurso de la historia, reconociendo un lugar a la subjetividad, facilitan hacer un giro subjetivo en el abordaje del pasado. Las religiosas fueron también herederas de una milenaria tradición eclesial que privilegió la carta como medio para fortalecer los vínculos entre los ausentes, alimentar la fe y sostenerse en la esperanza.

Para las dominicas del siglo XIX, las cartas, las conversaciones en el locutorio conventual y las prácticas confesionales ${ }^{43}$ fueron los medios privilegiados de comunicación de la intimidad, a la vez que fortalecieron el proceso de adquisición de la nueva identidad religiosa que habían decidido asumir y constituyeron el lugar donde ese proceso se ejerció. ${ }^{44} \mathrm{~A}$ su vez asistimos, para la segunda mitad del siglo XIX, a un gran desarrollo de circulación de correo que contribuyó a facilitar la comunicación íntima y el desciframiento del yo en el diálogo escrito. Junto a este proceso se afinaron los mecanismos de identificación (registro civil, censos, padrones electorales, difusión del retrato fotográfico, huellas digitales, utilización del lecho

${ }^{42}$ Nora Bouvet, La escritura epistolar (Buenos Aires: Eudeba, 2006), 14.

${ }^{43} \mathrm{Me}$ he referido a las prácticas confesionales en Cynthia Folquer, "Aprendiendo a hablar de sí misma. Las cartas de Fr. Ángel Boisdron a Sr Juana Valladares”, Revista Itinerantes. Historia y Religión, año 1(1) (2011): 159-178; "La construcción de la subjetividad femenina en Tucumán. Las epístolas de Fr. Boisdron (1891-1920)”, Revista Telar (4) (2006): 70-93.

${ }^{44}$ Victoria Cohen Imach, Redes de papel. Epistolas conventuales (Tucumán: Universidad Nacional de Tucumán, 2004), 21. 
individual que favoreció la autonomía) que tendieron a fortalecer la individualidad y la exaltación del yo. ${ }^{45}$

Las relaciones epistolares entre las dominicas de Tucumán produjeron cartas de organización, formales, cartas obligadas, pero también cartas entre amigas, cartas de intimidad, de consuelo y desahogo. Michel Foucault ${ }^{46}$ expresaba que la escritura epistolar destinada a otro, por definición, da lugar también a una "escritura de si" al instalar un cara a cara; abrirse a la mirada del otro, constituye una cierta manera de manifestarse ante sí y ante los demás. Por ello escribir es mostrarse, hacerse ver, hacer surgir el propio rostro ante el otro. La carta es revelación de sí bajo la mirada del destinatario.

La correspondencia privada permite adentrarnos en la intimidad como una herramienta para la comprensión de las transformaciones históricas. La función doble de lo íntimo -punto ciego y lugar de paso-, espacio para transgredir la oposición entre público y privado, se impone en los abordajes de una fenomenología de la interioridad. ${ }^{47}$

Las cartas aquí analizadas nos abren la subjetividad de las mujeres religiosas que se fue cimentando en torno a sus relaciones epistolares como afirma Victoria Cohen Imach,

en la medida en que la escritura epistolar involucra necesariamente a la primera persona, constituye un espacio especialmente apto para la configuración y afirmación de la subjetividad de la esposa de Cristo, pero también para la inscripción de las dificultades, avances y retrocesos de esa misma afirmación. ${ }^{48}$

Las cartas escritas por Elmina Paz, dan cuenta de estas relaciones, a la vez que reflejan la vida cotidiana y los procesos subjetivos de su itinerario vital.

${ }^{45}$ Alain Corbin, "Entre Bastidores", en Historia de la vida privada, tomo 4. De la Revolución Francesa a la Primera Guerra Mundial, Philippe Arìes y Georges Duby, 398408 (Madrid: Taurus, 2001),

${ }^{46}$ Michel Foucault, "La escritura de sî", en Los senderos de Foucault, Tomás Abraham, cit. en Nora Bouvet, La escritura epistolar, 85.

${ }^{47}$ Nora Catelli, En la era de la intimidad (Rosario: Beatriz Viterbo, 2007), 10.

${ }^{48}$ Victoria Cohen Imach, Redes de papel, 81. 
Las epístolas constituyen el vehículo privilegiado para adentrarnos en una de las actividades más comunes en la celda conventual: la escritura. El corpus que analizo está constituido por 179 cartas escritas por Elmina Paz ${ }^{49}$ que nos permiten recorrer el paisaje interior de las dominicas de Tucumán, percibir el proceso de configuración de la subjetividad femenina y las representaciones delineadas para mujeres religiosas en la segunda mitad del siglo XIx. Los procesos de subjetivación se conforman a partir de modelos o normas imperantes en el interior de una determinada formación discursiva y más ampliamente en la sociedad. Coincido con Victoria Cohen Imach en el rol fundamental que ejerce el lenguaje y la escritura al nutrir la propia experiencia del sujeto. ${ }^{50}$

Las cartas manifiestan también su naturaleza contradictoria, "por una parte favorece la manifestación de pensamientos o emociones que no se osaría mostrar cara a cara y por otra enfría la relación y acentúa el desamparo, la soledad o la reserva", como expresa Barrenechea. $^{51}$

Advierte Cohen Imach que la carta en los ambientes claustrales "resulta capaz de suavizar y al mismo tiempo preservar los rigores de la vida conventual: el relativo aislamiento de la ciudad circundante, el encierro, la soledad. Al escribir, la religiosa simultáneamente niega y afirma la clausura, vive y muere al mundo, se ofrece y se repliega". ${ }^{52}$

El proceso de fundación de la congregación de hermanas dominicas del Santísimo Nombre de Jesús, en el último cuarto del siglo xIX,

${ }^{49}$ Todavía el archivo de las dominicas está en proceso de catalogación, las cartas de Elmina Paz clasificadas hasta el momento son 179. La familia Paz conservó en su archivo familiar 69 cartas dirigidas por Elmina a su hermano Benjamín y 70 cartas dirigidas a la esposa de Benjamín, Dalmira Colombres de Paz. Se conservan 4 cartas dirigidas a todas las hermanas de la Congregación y 32 cartas individuales (16 a Teresa López Alurralde, 6 a Juana Valladares, 4 a Enriqueta Toscano, 2 a Benjamina Toledo, 2 a Catalina Zavalía, 2 a Rosa Pérez, 1 a Rosario Coutteret y 3 sin nombre). También se han guardado 3 cartas dirigidas al obispo de Tucumán, Pablo Padilla y Bárcena y 1 al presidente del Consejo Nacional de Educación.

${ }^{50}$ Victoria Cohen Imach, "Escribir desde el claustro. Cartas personales de monjas", Revista Telar (1) (2004): 28.

${ }^{51}$ Ana María Barrenechea, "La epístola y su naturaleza genérica”, Dispositio 15(39) (1990): 51-65.

${ }^{52}$ Victoria Cohen Imach, Redes de papel, 20. 
implicó un intenso intercambio epistolar entre las mujeres que estaban estableciendo las bases de los nuevos conventos, asilos y colegios. Las cartas van tejiendo la estructura organizativa de la nueva fundación a la vez que fortalecen lazos de amistad y ayuda mutua. Los asuntos de la vida cotidiana impregnan las epístolas: discernimientos, elecciones, nombramientos, situaciones de enfermedad, criterios de cuidado de los huérfanos, solicitudes de ayuda económica, etcétera.

Se observan fórmulas de saludo y despedida y algunos estilos ciertamente pautados de la escritura epistolar conventual. Pero como afirma Beatriz Ferrus Anton "tras un texto aparentemente pautado hasta la minucia, se escoden un decir y un saber específicamente femeninos". ${ }^{53}$

Las cartas de Elmina son así cartas de fundación y organización - cartas pragmáticas- pero también cartas de exhortación o amonestación que orientan hacia el cuidado de la vida de los más vulnerables. Emergen cartas de intimidad, cartas que denotan el camino espiritual personal o de sus destinatarias y cartas de confianza en sus familiares más cercanos.

En este trayecto de mi investigación propongo una aproximación a las cartas de intimidad, las que se refieren al camino espiritual y al cuidado de la vida de los huérfanos a ellas encomendados.

\section{LA INTIMIDAD EN LA AUSENCIA: ${ }^{54}$ CARTAS DE CONFIANZA Y DESAHOGO}

Las cartas escritas por Elmina a su hermano Benjamín y su esposa Dalmira reflejan confianza, apertura del corazón e intimidad. Elmina escribe confiada, busca que sus familiares cercanos la recuerden, anhela estar presente ante ellos.

${ }^{53}$ Beatriz Ferrus Anton, "Dos experiencias, un destino: Sor María de Jesús de Agreda y Sor Francisca Josefa de la Concepción del Castillo", en Sor María de Jesús Agreda y la literatura conventual femenina en el Siglo de Oro, ed. Miguel Zugasti, 55 (Soria: Cátedra Internacional Alfonso VIII, 2008).

${ }^{54} \mathrm{La}$ "intimidad en la ausencia" es el título de un precioso artículo sobre el género epistolar de Patrizia Violi, "La intimidad en la ausencia: formas de escritura epistolar", Revista de Occidente (68) (1987): 87-99. 
$\mathrm{Al}$ recibir el hábito religioso y asumir el nuevo nombre de mujer consagrada a Dios, le escribe a su hermano expresando la transformación que experimenta y una profunda confianza:

Ayer fue el día que la Iglesia celebra el Dulce Nombre de Jesús, día en que la Divina Providencia había elegido para que vistiera el santo hábito con las demás hermanitas, lo recibimos de manos del Seńor Vicario con toda la solemnidad posible en nuestra pobre capillita de tantos recuerdos. $\mathrm{Mu}-$ cho he rogado por ti y demás familiares y cuanto he podido por mis amados vivos y difuntos en este día venturoso en que mi buen Jesús me colmaba de sus gracias, dándome una dulce paz en mi alma y un no sé que de confianza que no puedo explicar, que atendía a mis pobres plegarias. Bendito sean Dios y su Madre Santísima. ${ }^{55}$

Al finalizar la carta lo hacía de esta manera: "los abraza tu hermana que en el siglo se llamó Elmina Paz de Gallo y hoy Sor María Dominga del Santísimo Sacramento". De esta manera Elmina daba cuenta de su decisión de consagración a Dios simbolizada en el cambio de nombre y de vestimenta.

Una vez sentadas las bases de la fundación de la congregación, relataba su experiencia a Benjamín: "que decirte que estoy buena y tranquila, aspirando a corresponder a nuestro buen Dios su inmensa bondad para con esta su indigna y tan miserable criatura" ${ }^{56}$

También a su cuñada Dalmira se refería con la misma estrategia de humildad de larga data, difundida en la escritura religiosa femenina:

recibí tu cariñosa carta de felicitación por mi profesión religiosa, te agradezco mi querida hermana, se ha consumado mi sacrificio a Dios, me considero dichosa, en este día tenía vivos deseos de cantar el Te Deum con todas mis débiles fuerzas, ahora mi buena hermana ruega al Señor y a su bendita Madre para que esta pobre y con tan poca inteligencia, cumpla con toda fuerza la misión que Dios le ha confiado. ${ }^{57}$

${ }^{55}$ Carta a Benjamín Paz, Tucumán, 16 de enero de 1888, caja: Cartas de Elmina Paz, fasc. Carta a familiares (AHDT).

${ }^{56}$ Carta a Benjamín Paz, Tucumán, 7 de julio de 1889.

${ }^{57}$ Carta a Dalmira Colombres, Tucumán, 19 de marzo de 1889. 
Las epístolas de Elmina a Benjamín reflejan sentimientos de angustia, pero también las alegrías del nuevo camino emprendido. Es a su hermano a quien le abre su corazón lleno de nostalgia por su amado esposo: "Estoy triste mi querido hermano, mañana hace una año que vi la mirada y oí la voz querida de mi Viejo, cuántos recuerdos tan dolorosos agobian mi destrozado corazón, hasta vos estás lejos de mí que me consolarías algo con tu cariño".$^{58}$

Cuando Elmina escribía esta carta, hacía pocos meses que se había calmado la epidemia de cólera en Tucumán y faltaban pocos días para que ella y el grupo de compańeras dieran sus primeros pasos en el postulantado, el primer paso de formación para convertirse en religiosas dominicas. La nostalgia de su esposo está entretejida con su decisión de asumir la vida religiosa dominicana. Pareciera que en esta carta a su hermano Elmina busca desentrañar su corazón, sentir por escrito, poner en orden sus sentimientos -como bien señala Diego Navarro Bonilla- para otras cartas de mujeres. ${ }^{59}$

Los sentimientos de preocupación también invaden a Elmina ante la decisión de fundar un nuevo colegio de señoritas, es Benjamín nuevamente su remanso en quien se desahoga:

Calcularás mi querido hermano bienhechor, conociendo mi genio, mi parquedad y mi timidez, la lucha que tendré con esto para vencer las dificultades y hacer lo que se ha resuelto que se haga, así que puedo decir con el Apóstol San Pablo que estoy de parto con tantas angustias y temores pero como el Apóstol, pongo toda mi confianza en la Divina Providencia que todo superará y hará lo que más convenga a la gloria de Dios. ${ }^{60}$

Elmina Paz sostuvo una relación epistolar con su hermano por muchos años, hay constancia de cartas desde 1882 a 1902, año en que falleció Benjamín. Con su cuñada Dalmira el intercambio se realizó por un largo periodo, se conservaron cartas desde 1864 a

${ }^{58}$ Carta a Benjamín Paz, Tucumán, 2 de junio de 1887.

${ }^{59}$ Diego Navarro Bonilla, "Sentir por escrito hacia 1650: cartas, billetes y lugares de memoria", en Accidentes del alma. Las emociones en la Edad Moderna, ed. María Tausiet y James Amelang, 229-254 (Madrid: Abada Editores, 2009).

${ }^{60}$ Carta a Benjamín Paz, Tucumán, 23 de noviembre de 1901. 
1910. Los vínculos familiares no sólo la contuvieron y apoyaron afectivamente, sino que le posibilitaron fortalecer sus redes sociales con miembros de elite política provincial y nacional que apoyaron su proyecto.

Ante la muerte de su hermano, la carta a su cuñada Dalmira contiene una profunda manifestación de sentimientos de hermandad familiar que perduraban en su vida de claustro:

Estoy triste, lloro a mi hermano, tu sabes mi querida hermana lo que fue para mí, como el Ángel del consuelo que el Señor me enviara en los dolores de mi pobre vida de seglar, en mi vida de religiosa y madre de tantas hijas religiosas y huerfanitas, era nuestro padre a quien le comunicaba mis consuelos como mis dificultades. ${ }^{61}$

\section{Artesanas del Cuidado de la Vida: Cartas Para PROTEger Y HACER SUSTENTABLE EL PROYECTO}

Las cartas de Elmina ponen en escena la vida cotidiana del convento, pregunta e informa sobre el estado de salud de cada hermana y de las huérfanas, manifiesta preocupación por la alimentación, informa de la muerte de las religiosas, familiares y amigos. Sus textos demuestran la obra de la civilización cotidiana, asumida por este grupo de mujeres, cuidando y dando vida a los más débiles, los siguientes párrafos indican este compromiso:

A la Madre Priora que cuando se ponga bien y pueda escribirme me avise si la hermana Rosarito se alimenta, que este es el punto principal que me preocupa de ella. ${ }^{62}$

Creo está de más encomendarle el cuidado de sus huerfanitas, que no anden sucias ni sus vestidos rotos y las acostumbre a que sean hacendosas y trabajadoras. ${ }^{63}$

${ }^{61}$ Carta a Dalmira Colombres, Tucumán, 17 de noviembre de 1902.

${ }^{62}$ Carta a una religiosa del Convento de Santiago del Estero, 27 de octubre de 1898.

${ }^{63}$ Carta a la Hna María Enriqueta Toscano, Tucumán, 9 de julio de 1901. 
Tenemos a nuestro lado a mi sobrina Carmen Paz, que ha estado en una situación lamentable con sus nervios y sus dolores la han confiado a mi cuidado y vemos con satisfacción como mejora gracias a Dios. ${ }^{64}$

A mi hija Sor Raimunda, que tengo noticias de que ya está allí, gracias a Dios, que salió del mal paso, que se cuide, se atienda, no desobedezca lo que le mande su médico y no se canse de dar gracias a Dios por tantos beneficios. ${ }^{65}$

A nuestro querido Dr. Julio que me haga la caridad de mandarme la receta de esa pomada para curar el catarro crónico de una hermana que él la vio y la de las pildoritas para mi, Dios les pagará la caridad que hacen conmigo y todo este asilo. ${ }^{66}$

El relato de la fundación de la segunda casa, expresa la intensidad de la vivencia de los vínculos entre las religiosas y la dolorosa primera separación. La escena de la despedida de las primeras hermanas rumbo a la ciudad de Monteros en la provincia de Tucumán, para realizar la apertura de un nuevo colegio, pone de manifiesto el estilo de relación establecido entre ellas:

se fueron el 11 a las 11 de la mañana, imagínate mi querida lo que será esta primera separación, en mi estado, me fui a los pies del Sagrario, para que me fortaleciera, se acercaron de una en una para pedirme la bendición pero apenas podía bendecirlas, hasta que una se abrazó de mis rodillas y no podía desprenderme con su llanto, el Señor me dio la fortaleza que le pedía, la levanté, la apoyé sobre mí, mi pobre corazón, así la conduje a la calle, la hice subir al coche, hasta verlas partir acompañadas de nuestro P. Ángel y el P. Roldán. ${ }^{67}$

El cuidado de la vida implicaba también el acompañamiento en el trance de la muerte, los gestos de ternura también se hacían presentes en ese momento crucial:

\footnotetext{
${ }^{64}$ Carta a la Hna Juana Rosa Valladares, Tucumán, 9 de abril de 1907.

${ }^{65}$ Carta a la Hna María Benjamina de Jesús Toledo, Tucumán, 24 de abril de 1908.

${ }^{66}$ Carta a Benjamín Paz, Tucumán, 25 de marzo de 1897.

${ }^{67}$ Carta a Dalmira Colombres, Tucumán, 14 de febrero de 1895.
} 
Se me olvidó darte la noticia de la muerte de mi hija Sor Elmina de los Santos Inocentes que como te anunciaba en varias de mis cartas su gravedad, después de 2 meses y medio casi de conocida la enfermedad, se nos fue a su verdadera Patria el 23 de Julio pasado. Su Divino Esposo, Jesucristo, la habrá recibido y tendremos una intercesora ante El, su enfermedad fue de muy poco sufrimiento con algunos días no más de cama, tranquila en su espíritu como siempre con ese candor y pureza que la distinguía y esa sumisión con que siempre decía -lo que quiera nuestra madre-. Pobrecita Dios me ha dado fuerza para que la atienda en todo, lavándole yo misma su carita y sus manos que estaban como de marfil con su Cristo, su Rosario y su coronita de rosas. ${ }^{68}$

La vida cotidiana de los conventos durante el siglo XIX estaba pautado por la producción de manufacturas, las huérfanas de los asilos colaboraban con este tipo de actividades para su sustento o para obsequiar a bienhechores. El bordado constituía una tarea educativa y por ello Elmina encargaba en Buenos Aires a su cuñada, la compra de hilos y telas:

Te envío unos $\$ 50$, para que me hagas el favor de comprarme géneros de hilo; quiero que las huerfanitas, que están un poco dispuestas ya, para el bordado, hagan sus primeras obritas para Uds. y Pedro; con la confianza que tengo con vos, mi querida hermana, te pido, veas el género que se necesita para 2 pares de fundas largas, para ustedes y las de Pedro; señala a donde querés que vayan las letras, nosotras beatas viejas no entendemos lo que se usa; si quieren que sean con punzó matizadas, mándame algunos dibujitos a propósito y una docena de madejitas, hilo de castilla no ${ }^{\circ} 10$; e hilo colorado de bordar que hay en "La Modista", si es que han de ir de color. ${ }^{69}$

La preocupación por las telas para la confección de ropa de las huérfanas está en el centro de sus preocupaciones: "dile que le dé las

${ }^{68}$ Carta a Dalmira Colombres, Tucumán, 15 de agosto de 1901. La referencia a la corona de rosas, pone de manifiesto que en Tucumán, se continuaba a fines del siglo XIX, con la tradición de colocar corona de rosas a las difuntas.

${ }^{69}$ Carta a Dalmira Colombres, Tucumán, 9 de julio de 1890. 
gracias por este socorro que me envió tan oportuno para sostener a nuestras pobres huerfanitas que tenemos seria necesidad de hacerle ropa"70.

La organización del asilo y la escuela, exigía que las cartas sean un eficaz vehículo de búsqueda de colaboración en distintas instancias particulares y estatales:

Por intermedio de la señora Da. Emilia L. de Zavalía conseguí que me prestara el señor Intendente Municipal unos bancos viejitos para la escuela de mis huerfanitos hasta que me manden los que me prometen la comisión de Educación de esa, según tú me decías, porque a mi no me ha contestado el Dr. Zorrilla, cuando vengan se abrirá la escuela para las pobrecitas de estos alrededores [...] No sé si Pedro recibiría una nota nombrándolo padrino en unión con su señora. Hasta hoy no he recibido sino ocho rollos de alambre y se siente la gran necesidad de la leña. ${ }^{71}$

El intermediario de muchas ayudas recibidas fue su hermano Benjamín, quien desde Buenos Aires tramitaba subsidios y establecía contactos. La asidua correspondencia con Benjamín, manifiesta la relación de confianza entre ambos hermanos:

No sé si te avisé que se construyó el edificio para la escuela, está muy lindo con sus ciento diez niñas, la antigua clase está cubierta de camas de huérfanos bien arregladitas, hay ochenta y dos Hermanas, esperando siempre en Dios, creo podemos sostenerlas.

En estos días he recibido dos mil pesos que había dejado Don Juan M. Méndez (q.p.d.) con esto y una parte que quedó de lo que tú nos hiciste dar allá, podemos hacer las oficinas más necesarias para los huérfanos en el tercer patio, como son, buenos lavaderos, una buena letrina, los baños, por que los que había no están bien [...] esperamos lo que nos dejó el pobre Miguel para componer los claustros y galerías. ${ }^{72}$

\footnotetext{
${ }^{70}$ Carta a Dalmira Colombres, Tucumán, 24 de febrero de 1898.

${ }^{71}$ Carta a Benjamín Paz, Tucumán, 23 de julio de 1889.

${ }^{72}$ Carta a Benjamín Paz, Tucumán, 20 de septiembre de 1882.
} 
Cuando se refiere a alguna de las huérfanas, exterioriza sus deseos de protección y cuidado cariñoso:

A mi huerfanita Dalinda que me alegré mucho con las buenas noticias que me han dado de ella, recibí también su cartita y es bueno que de vez en cuando me escriba. A mi hija Filomena que le envío mis bendiciones igualmente que a V.R., abrazándolas carińosamente su madre en el Señor. ${ }^{73}$

\section{“Está MUY FlOJA PARA AFRONTAR LA CRUZ": LAS CARTAS DE EXHORTACIÓN}

Por otra parte, Elmina asume un tono firme al exhortar o amonestar a las hermanas cuando su testimonio no es edificante para las huérfanas. Es consciente que la caridad fraterna es el criterio de verificación de toda la vida cristiana, expresa que ha sentido su "alma abatida" por las veces que ha percibido la ausencia de un auténtico amor, que ha provocado escándalo entre los nińos y los laicos: "como se ha abatido mi alma considerando el número infinito de veces que desedificamos a nuestras hermanas y si sólo fuera a nuestras hermanas! pero muchas veces también a las niñas y a los seglares con quienes tratamos y que esperan ver en nosotros modelo de perfección cristiana!" ${ }^{74}$

A la hermana Juana Valladares, quien se quejaba por las clases que tenía que dar a las huérfanas, pero, sin embargo, buscaba hacer algún tipo de ayuno más exigente, le respondía citando la enseñanza de Enrique Susón: ${ }^{75}$

¿Para que quiere mi hija que vuelva, si ni mis sermones, ni mi presencia en esa, la consuelan? Está V.R. muy floja para cargar la cruz que el Señor le ha impuesto por medio de la santa obediencia y la que sin duda le será más agradable a Él que la cruz con clavos que se impuso (según [explica] Enrique Susón).

${ }^{73}$ Carta a Teresa López Alurralde, Tucumán, sin fecha.

${ }^{74}$ Carta a las Hermanas de la Congregación, Tucumán, 9 de septiembre de 1907.

${ }^{75}$ La lectura de Enrique Suson (Heinrich Seuse) puso en contacto a las dominicas de Tucumán con la tradición dominicana de mística renana. 
Así mi hija Ud. agradará más al Sagrado Corazón estudiando la pedagogía para enseñar y hacer adelantar a esas criaturas confiadas a su cuidado para instruirlas, que haciendo esa colación que yo no le doy importancia ninguna. Hablando con N. Padre sobre esto, se sonrió y me dijo, que no les afloje y que lo que se ha ordenado, en el Capítulo General, sobre los ayunos es para todas.

El obsequio que Ud. le va a ofrecer al Sagrado Corazón es el de dar las tres clases que el dejé ordenado y comer bien, para que pueda trabajar mucho para gloria del Sagrado Corazón de su divino Esposo, sin perder el tiempo. ${ }^{76}$

Vemos en este ejemplo un cambio en la comprensión del crecimiento espiritual, se busca en la segunda mitad del siglo XIX, que las mujeres consagradas a Dios sean útiles a los demás con la enseñanza y se valora la actividad y el servicio a los niños más que el sacrificio corporal con ayunos inútiles.

La exhortación a vivir la caridad como única vía para superar el engaño en la imitación de Jesucristo, se hace evidente en otra carta dirigida a todas las religiosas de la congregación:

Las hermosas meditaciones que hemos hecho en estos días de Pascua, me han movido a dirigiros unas cuantas palabras de exhortación sobre la caridad fraterna, ya que no me es posible hacerlo hablándoles personalmente. Nuestra humilde y naciente Congregación, aunque pequeña todavía, cuenta ya con cinco casas y yo advierto que en ninguna de ellas hay esa paz, esa unión que Jesucristo pedía a su Padre Celestial para sus Apóstoles y discípulos; y que en el día de su resurrección cuando se les apareció a todos reunidos, les dio esta paz repitiéndoles hasta tres veces estas consoladoras palabras: "Paz con vosotros". Estas consideraciones mis queridas hijas me impulsan a recomendaros que seáis amables y caritativas con todas vuestras Hermanas disculpando sus faltas y defectos, no hablando de ellos si no es con vuestros Superiores para que los remedien. Que cada una se esfuerce en hacer cuanto esté de su parte para conservar esta caridad y unión de los ánimos en la Comunidad, teniendo siempre presente estas

${ }^{76}$ Carta a Juana Valladares, Tucumán, 6 de junio de 1899. 
dos condiciones principales de la caridad y de la paz, que las habéis meditado estos días: soportar los defectos de los otras; no dar nada que soportar a las demás. ${ }^{77}$

En cuanto a la educación de las huérfanas se pone de manifiesto una superación de las prácticas pedagógicas antiguas centradas en el castigo y la humillación, el consejo de Elmina Paz a las hermanas a cargo de los asilos es claro en este aspecto: "Nunca sean vuestras correcciones con palabras hirientes, ni en voz alta, sino al contrario con frases dulces y caritativas, dirigidas con algún acento de severidad y cierta dignidad que siempre causan muy buen efecto y son suficientes para corregirlas al mismo tiempo para educarlas". ${ }^{78}$

\section{A MODO DE CONCLUSIÓN}

Las cartas de Elmina Paz de Gallo revelan que a pesar del bajo nivel de cultura formalizada accesible a las mujeres en el Tucumán de la segunda mitad del siglo XIX, el género epistolar fue intensamente desarrollado en la vida conventual femenina. Esta mujer fundadora fomentó relaciones epistolares para contribuir a la formación de las religiosas de su congregación y diseńar el nuevo proyecto educativo y conventual que surgía en Tucumán. Las cartas forjaron identidades personales y colectivas, que constituyeron este intercambio en un espacio de desarrollo de la subjetividad e interiorización de diversas dimensiones culturales.

Estos textos fueron un ámbito de intimidad en la distancia, una manera de romper las barreras pautadas por la clausura. A través de las cartas, las dominicas fueron aprendiendo a cuidar la vida de los más vulnerables, intercambiaron consejos para educar mejor, gestionaron apoyos económicos y alimentaron relaciones de amistad. También las cartas amonestaron y exhortaron al crecimiento espiritual, al cuidado de los huérfanos e invitaron a vivir un itinerario espiritual. La escritura de Elmina Paz refleja las lecturas bíblicas y de

${ }^{77}$ Carta de Pascua a las Hermanas de la Congregación, sin fecha.

${ }^{78}$ Carta a las Hermanas de la Congregación, 31 de diciembre de 1897. 
autores espirituales que se realizaban en el convento. He buscado en este trayecto de mi estudio centrar la mirada en los sentimientos, el compromiso femenino con el cuidado de la vida y el rol de educadora asumido por esta mujer fundadora. Otros temas no analizadas en esta oportunidad que esperan ser estudiados exhiben interpretaciones sobre los cambios políticos de la Argentina decimonónica, las transformaciones del Estado, el incipiente proceso de secularización de la sociedad, la evolución en el sistema de las creencias de las dominicas, entre otros tópicos. ${ }^{79}$

\section{FuENTES INÉDITAS}

Archivo Hermanas Dominicas de Tucumán

Cartas de Elmina Paz de Gallo

Cartas de Fr Ángel María Boisdron

Tomasa Alberti, Biografía de Elmina Paz-Gallo

\section{Fuentes PUblicadAS}

"La escuela primaria en Tucumán”. En Álbum General de la Provincia de Tucumán en el primer Centenario de la Independencia Argentina. Buenos Aires: Establecimiento Gráfico Rodríguez Giles, 1916.

Constituciones de las Hermanas Dominicas de la Tercera Orden Regular en su Congregación del SS. Nombre de Jesús de Tucumán, República Argentina. Friburgo: Imprenta y Librería de la Obra de San Pablo, 1893.

BoisDron, Ángel María, "La intelectualidad de la mujer”. En Discursos y escritos. Buenos Aires: Presuche y Eggeling, 157-160.

${ }^{79}$ Es interesante el estudio de los tópicos de las cartas conventuales realizado por Elena Giménez Alvira, para el siglo XVI-XvıI espańol, sería muy provechoso hacer una lectura comparativa de los cambios y continuidades con los que emergen en la vida conventual del siglo XIX en Tucumán, véase “'Cartas al dictado'. El epistolario de la Madre Isabel de Santo Domingo (Convento de San José de Carmelitas descalzas de Zaragoza)”, en Letras en la celda, 255-271. 
Bibliografía

Baranda Leturio, Nieves y María del Carmen Marín Pina, eds. Letras en la celda. Cultura escrita de los conventos femeninos en la España moderna. Madrid y Frankfurt: Iberoamericana-Vervuert, 2014.

Barrenechea, Ana María. "La epístola y su naturaleza genérica”. Dispositio 15(39) (1990): 51-65.

Ben altabef, Norma. "Educar en Tucumán en la primera mitad del siglo XIx. El modelo pedagógico colonial y el nuevo modelo educativo. Permanencias e iniciativas". En La República Extraordinaria. Tucumán en la primera mitad del siglo XIX, coord. Gabriela Tío Vallejo. Rosario: Prohistoria, 2011.

Bouvet, Nora. La escritura epistolar. Buenos Aires: Eudeba, 2006.

Catelli, Nora. En la era de la intimidad. Rosario: Beatriz Viterbo, 2007.

Cerviño, Rodolfo. "El primer colegio secundario de mujeres en Tucumán, Colegio Sarmiento". Revista de la Junta de Estudios Históricos de Tucumán, año 7(4) (julio 1974), 189-200.

Cohen IMAch, Victoria. "Escribir desde el claustro. Cartas personales de monjas". Telar (1) (2004): 28-37.

. Redes depapel. Epistolas conventuales. Tucumán: Universidad Nacional de Tucumán, 2004.

Corbin, Alain, "Entre Bastidores". En Historia de la vida privada. De la Revolución Francesa a la Primera Guerra Mundial. Tomo 4. Philippe Ariès y Georges Duby, 391-603. Madrid: Taurus, 2001.

Craveri, Benedetta. La cultura de la conversación. Buenos Aires: Fondo de Cultura Económica, 2004.

De Certeau, Michel. "Leer una cacería furtiva”. En La invención de lo cotidiano I. Las artes de hacer. México: Universidad Iberoamericana, 2000, 177-189.

Dufourq, Elizabeth. Les Aventurières de Dieu, trois siècles d'histoire missionnaire française. París: Du Cerf, 2009.

Kordic Riquelme, Raïssa. "Prólogo y edición crítica". Epistolario de sor Dolores Peña y Lillo (Chile, 1763-1769). Madrid: Universidad de Navarra, Iberoamericana-Vervuert, 2008. 
Ferrus Anton, Beatriz. "Dos experiencias, un destino: Sor María de Jesús de Agreda y Sor Francisca Josefa de la Concepción del Castillo". En Sor María de Jesús de Agreda y la literatura conventual femenina en el siglo de oro, ed. Miguel Zugasti. Soria: Cátedra Internacional Alfonso VIII, 2008.

Folquer, Cynthia. "Somos hombres y yo más que ninguno. Los escritos autobiográficos de Fr. Ángel María Boisdron, 1876-1924”. En Actas II Jornadas de Historia de la Orden Dominicana en Argentina, coord. Cynthia Folquer, 165-185. Tucumán, unSTA, 2005.

. "La construcción de la subjetividad femenina en Tucumán. Las epístolas de fray Boisdron (1891-1920)". Telar (4) (2006): 70-93.

. "La elite local de Tucumán en la construcción del Estadonación argentino. El caso de Benjamín Paz y Elmina Paz de Gallo (fines del siglo XIX-principios del siglo $\mathrm{xx}$ )". Revista de Indias LXVII (240) (2008): 433-458.

. "Olvidarme de mi: Elmina Paz o la apertura al otro". Duoda (34) (2008): 33-54.

. "Escribir de sí: interioridad y política en las mujeres de Tucumán (fines de siglo XIX y principios del Xx)”, en Sociedad, cristianismo y politica. Tejiendo historias locales, coord. Cynthia Folquer y Sara Amenta, 191-228. Tucumán: UNSTA, 2010.

. "Cólera morbus y cólera divina. Miedo, epidemia e imaginario religioso. Tucumán, 1886-1887”. Boletín Americanista, año LXI (62) (2011): 73-96.

. "Aprendiendo a hablar de sí misma. Las cartas de Fr. Ángel Boisdron a Sr Juana Valladares". Revista Itinerantes. Historia y Religión (1) (2011): 159-178.

- Viajeras hacia el fondo del alma. Sociabilidad, politica y religiosidad en las Dominicas de Tucumán, 1886-1910. Tesis de Doctorado en Historia. Barcelona: Universidad de Barcelona, 2012. http://www.tesisenred.net/handle/10803/96263

Fraschina, Alicia. Mujeres consagradas en el Buenos Aires colonial. Buenos Aires: Eudeba, 2010.

Gargiulo, María Cecilia. "El cólera: oportunidades de control y resistencias populares. Tucumán, 1886-1887”. Estudios Sociales, ańo XXI (41) (segundo semestre 2011): 97-125. 
Herrera, María Haydée. Elmina Paz. Heredera e iniciadora. Una biografia teológica. Tucumán: UNSTA, Fundación Elmina PazGallo, 2011.

Kordic Riquelme, Raïssa. Prólogo y edición crítica. Epistolario de Sor Dolores Peña y Lillo (Chile, 1763-1769). Madrid: Universidad de Navarra, Iberoamericana-Vervuert, 2008.

LaVRIn, Asunción. "De su puño y letra: epístolas conventuales". En El monacato femenino en el imperio español, coord. Manuel Ramos Medina, 43-62. México, Condumex, 1995.

. "La celda y el siglo: epístolas conventuales". En Mujer y cultura en la Colonia hispanoamericana, ed. Mabel Morańa, 139-159. Pittsburg: Instituto Internacional de Literatura Iberoamericana, 1996. . "Los senderos interiores de los conventos de monjas". Boletín

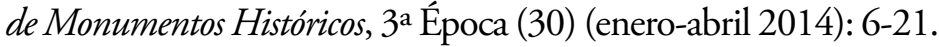
Lavrin, Asunción y Rosalva Loreto López, eds. Monjas y beatas. La escritura femenina en la espiritualidad barroca novohispana. Siglos XVII y XVIII. México: Universidad de las Américas-Puebla, Archivo General de la Nación, 2002.

Lavrin, Asunción y Rosalva Loreto López, eds. Diálogos espirituales. Manuscritos femeninos hispanoamericanos. Siglos XVI-XIX. México: Universidad Autónoma de Puebla, Universidad de las Américas-Puebla, 2006.

LionetTi, Lucia. "La educación de las mujeres en América Latina: formadoras de ciudadanos". En Historia de las mujeres en España y América Latina. Vol. III, dir. Isabel Morant, 849-869. Madrid: Cátedra, 2006.

Navarro Bonilla, Diego. "Sentir por escrito hacia 1650: cartas, billetes y lugares de memoria". En Accidentes del alma. Las emociones en la Edad Moderna, eds. María Tausiet y James Amelang, 229-254. Madrid: Abada Editores, 2009.

Parolo, Paula, Daniel Campi y María Estela Fernández, “Auge azucarero, mortalidad y políticas de salud en San Miguel de Tucumán en la segunda mitad del siglo xIx". Estudios Sociales, año xx (38) (primer semestre 2010): 39-72.

Rosillo LuQue, Aracelli. "La biblioteca antigua del convento de dominicas de Ntra. Sra. dels Àngels i Santa Clara de Manresa 
(siglos XVII-XIX): notas para su estudio a partir del inventario". En Letras en la celda. Cultura escrita de los conventos femeninos en la España moderna, ed. Nieves Baranda Leturio y María Marín Pina, 237-252. Madrid y Frankfurt: Iberoamericana-Vervuert, 2014. ScotT, Nina. "Escritoras hispanoamericanas del siglo XIx". En Historia de las mujeres en España y América Latina. Vol. III, dir. Isabel Morant, 693-721. Madrid: Cátedra, 2006.

Serrano, Sol. Virgenes viajeras. Diarios de religiosas francesas en su ruta a Chile. 1837-1874. Santiago: Universidad Católica de Chile, 2001.

"El poder del obediencia: religiosas modernas en la sociedad chilena del siglo XIX". En Las mujeres en la construcción de las sociedades iberoamericanas, coord. Pilar Gonzalbo Aizpuru y Berta Ares Quija, 295-313. Sevilla y México: Consejo Superior de Investigaciones Científicas, El Colegio de México, 2004.

Solari, Manuel. Historia de la Educación Argentina. Buenos Aires: Paidós, 1972.

Teitebaum, Vanesa. "Hacia una política social. Higiene y trabajo en Tucumán del entresiglo". Anuario IEHS (24) (2009): 41-68.

Torras Francés, Mary. Tomando cartas en el asunto. Las relaciones peligrosas de las mujeres con la literatura epistolar. Zaragoza: Prensa Universitaria, 2001.

VIOLI, Patricia. "La intimidad de la ausencia: formas de escritura epistolar". Revista de Occidente (68) (1987): 87-99.

ZARRI, Gabriela. "La escritura monástica". En Letras en la celda. Cultura escrita de los conventos femeninos en la España moderna, ed. Nieves Baranda Leturio y María Marín Pina, 49-64. Madrid y Frankfurt: Iberoamericana-Vervuert, 2014. 